\title{
ENGINEERING DESIGN ASPECTS OF THE HEATPIPE POWER SYSTEM
}

\author{
Brent Capell \\ University of Michigan \\ 810 Barton Dr. \\ Ann Arbor, MI 48105 \\ (313)936-0266 / Fax: (313)763-4540 \\ bcapell@engin.umich.edu
}

\author{
Marc Berte \\ Massachusetts Institute of Technology \\ 54 Pearl St. \#1 \\ Cambridge, MA 02139 \\ (617)492-6055 \\ mvberte@mit.edu
}

\begin{abstract}
The Heatpipe Power System (HPS) is a near-term, low-cost space fission power system designed at Los Alamos National Laboratory that can provide up to $1000 \mathrm{kWt}$ for many space applications. The design of the reactor is simple, modular, and adaptable. The basic design allows for the use of a variety of power conversion systems and reactor materials (including the fuel, clad, and heatpipes). This paper describes a project that was undertaken to develop a database supporting many engineering aspects of the HPS design. The specific tasks discussed in this paper are: the development of an HPS materials database, the creation of finite element models that will allow a wide variety of investigations, and the verification of past calculations.
\end{abstract}

\section{MATERIALS INVESTIGATIONS}

The Heatpipe Power System (HPS) design allows for a wide choice of materials for each HPS component. The main components of interest are the fuel, cladding, heatpipes, and support structure. Each of these components has a large number of possible materials to choose from; however, some early considerations narrowed the scope of this study. For near-term designs, the fuel is limited to a choice between uranium dioxide and uranium nitride because of the existing nuclear experience with these materials. Also, to enhance the manufacturability of the core, the fuel cladding, support, and heatpipes should be made of the same or very similar materials. This section will progress through some potential HPS materials, discussing each material individually followed by a comparison section.

\section{Molybdenum}

The majority of HPS materials will be composed of refractory metals; one material particularly well suited for several HPS applications is molybdenum. Molybdenum has a very high melting point and very good thermal conductivity. Molybdenum also has favorable neutronic properties for a passively safe, fast-spectrum reactor.

While polycrystalline molybdenum is well suited for the HPS, single-crystal molybdenum may offer even more potential. Single-crystal molybdenum is a actually an alloy consisting of molybdenum with $3 \%$ niobium (Mo3 $\mathrm{Nb}$ ). It was developed in the former Soviet Union in support of the TOPAZ-II thermionic space reactor. A positive attribute of this material is that because it is a single crystal, the creep rate is quite low (Nikolaev 1993). This property makes it ideal for use in thermionic systems, where small dimensional changes can result in large power output changes.

The development of this material in the former Soviet Union may complicate its use. The supporting database, with the exact properties and manufacturing experience, is largely proprietary. Use of this material could, however, begin to show the wealth of information available in Russia for high-tech applications.

Molybdenum, and most other refractory metals, reacts with oxygen at elevated temperatures. This property limits use of this material in certain environments.

\section{Niobium-1\% Zirconium}

Niobium-1\% zirconium ( $\mathrm{Nb} / \mathrm{Zr})$ is another refractory metal with a high melting point and good thermal properties. PWC- 11 is a similar alloy consisting of Niobium, $1 \%$ zirconium, and $0.1 \%$ carbon, which showed better properties during initial investigations. However, recent experience with PWC-11 does not support initial claims, and work still centers around $\mathrm{Nb} 1 \mathrm{Zr}$. It exhibits low corrosion in liquid metal systems, but does react with oxygen at elevated temperatures. 
This alloy was the center of investigation as a cladding material for the SP-100 liquid-metal-cooled, fast reactor developed by the United States in the latter part of the 1980s (Makenas 1994). During this project, an ambitious experimental program was undertaken to investigate the properties of the alloy under reactor conditions. Many of the tests were centered around irradiating fuel pins with various fuels and barrier materials. The barrier materials were used to limit gas diffusion from uranium nitride into the cladding materials investigated, or zirconium vapor transport to the fuel (Mason 1988). Although tests focused on uranium nitride fuels, uranium dioxide fuel was also used for initial tests. $\mathrm{Nb} 1 \mathrm{Zr}$ exhibited good irradiation performance, and suitable barriers were determined for the nitride fuel.

\section{Inconel}

Inconel is a high nickel alloy that is currently used for a variety of applications both in nuclear and non-nuclear systems. Because of its wide use, a large database of experience exists, and the properties are well established. The corrosion resistance of Inconel is very good. To further investigate the corrosion properties, experiments in a simulated Martian atmosphere have been proposed and hopefully can be undertaken at Brookhaven National Laboratory.

However, although some properties are better or comparable to refractory metals, Inconel has a relatively low melting point compared with the refractory metals and also has lower thermal conductivity. The low melting point and reduced thermal conductivity mean that a core made from Inconel will have a reduced power output. Calculations indicate that the power of an Inconel system will be approximately one-fifth the power of a refractory metal system with the same geometry. The power rating of an Inconel system (actually of any HPS system), can be increased by decreasing the pin size and/or changing the module geometry.

\section{Molybdenum-41\% Rhenium}

Molybdenum-41\% Rhenium (Mo41Re) is another refractory metal. Alloys of molybdenum and rhenium have been investigated for at least 20 years and are available for use. This alloy was investigated for use in the NEBA series of space reactors.

Mo41Re shows (1) good properties, (2) manufacturability, and (3) favorable neutronic properties for use in the fastreactor spectrum used in the HPS. This is because during water immersion, the presence of the rhenium decreases the k-effective; the water thermalizes the neutron spectrum, and the thermal neutrons are captured by rhenium's very large absorption resonances. During normal operation though, little or no difference is noted by the use of Mo41Re; however, the addition of rhenium increases the already high density of molybdenum to $14.2 \mathrm{~g} / \mathrm{cm}^{3}$, thereby increasing the mass of the reactor.

\section{MATERIALS CHOICES FOR GENERAL USES}

The optimum choice of materials for the HPS depends largely on what application the system will be used for. Two major groupings, space based and planetary and their impact on material selection, are discussed below. The environment and requirements dictate the pool of available choices.

\section{Space Reactor}

For a reactor to be used in space (outside of any planetary atmosphere), the absence of oxygen and other corrosive elements allows for the use of refractory metals. Because of their superior melting points and excellent thermal properties, reactors using refractory metals can operate at a nominal heatpipe temperature of $1400 \mathrm{~K}$, increasing the efficiency of the reactor and the available power output.

The exact choice of the refractory metal depends on several factors. Single-crystal molybdenum appears to have the best combination of nuclear, thermal, and mechanical properties, and allows higher power output if one or more heatpipes fail. However, use of this material for a US system may require a significant research effort to verify Russian data. Polycrystalline molybdenum could also be used, although its properties are not quite as favorable as single-crystal molybdenum. $\mathrm{Nb} 1 \mathrm{Zr}$ allows very acceptable performance and has been well categorized by US researchers. Mo41Re offers specialized properties that may be desirable for some applications. The use of Mo41Re increases the mass of the reactor, but limited use of this material may be desired to further ensure passive shutdown 
of the reactor under credible accident scenarios. Other refractory metals that may be considered are tungsten, rhenium, iridium, and tungsten-rhenium alloys.

\section{Planetary Reactor}

A planetary reactor would be used to support exploration within the atmosphere of a planet or moon, including manned missions to the surface of Mars. The presence of oxygen in the atmosphere may preclude the use of plain refractory metals because of their chemical reactivity. This leaves two options: modification of refractory materials, and non-refractory materials.

Modifications to refractory metals could include new alloys and the use of passivating films. New alloys would need to undergo major proving tests, which are generally undesirable. Passive films have been developed, but their use is very questionable. Passive films tend to degrade very quickly if small flaws, such as a scratch, are present. The only nonrefractory metal currently under major investigation is Inconel. As noted above, however, the use of Inconel would mean a major loss in available power compared with initial designs. Other materials, such as ferritic steels, may be applicable, but more research would have to been done. For near-term use, Inconel appears to be the best option despite the potential performance penalty.

\section{FINITE ELEMENT MODEL}

The use of finite element modeling (FEM) has grown with the increase in available computer power. FEM allows for the examination of many types of behavior such as deformation, heat transfer, and fatigue. To allow investigation of these behaviors, a solid model of the reactor was generated. The solid model was generated using Structural Dynamics Research Corporation's (SDRC's) I-DEAS Artisan series software. The Artisan series is largely a solid modeling program, but links to SDRC's I-DEAS Master Series, which can be used for finite element analysis. The model of the reactor was generated, but no finite element analysis has been completed.

\section{VERIFICATION OF CALCULATIONS}

Two designs, 250- and 1000-kWt cores, were chosen for verification because their power levels bound a wide range of potential missions. First, designs were examined using MCNP-4B for criticality calculations. All cores used single-crystal molybdenum for cladding and structure material. Calculations verified that both the 250- and $1000-\mathrm{kWt}$ cores have sufficient excess reactivity at beginning-of-life, and that they have a sufficient shutdown margin under all credible accident scenarios. Mo4lRe heatpipes are used in the 1000-kWt core to help achieve these conditions.

The heat-transfer and temperature distribution characteristics were examined using a computer code written specifically for the geometry of this reactor. Limits were placed on the temperature of each material, and the maximum power was computed. Power levels are computed so that with a loss of one heatpipe, nominal power is still maintained without exceeding temperature limits. Both reactors are within design goals. The limiting condition was found to be multiple heatpipe losses in adjacent modules when only radiation is assumed. Both of these events are worst-case scenarios and should represent extreme conditions. In all cases, radial and axial heat flux limits are not exceeded in the heatpipes.

Burnup was estimated for both reactors using MONTEBURNS (Poston 1997), which is a linkage code between MCNP (Briesmeister 1993) and ORIGEN (Croff 1980). It operates by making multiple MCNP runs computing estimated isotopic concentrations between runs at specified timesteps. Isotopes can be specifically watched, or watched automatically if their concentration is deemed important. Runs were performed for a 10-year lifetime for both cores. For the $250-\mathrm{kWt}$ core the decrease in excess reactivity was found to be $<1 \%$. For the $1000-\mathrm{kWt}$ core the decrease in excess reactivity was found to slightly $>1 \%$. 


\section{CONCLUSIONS}

The HPS has not encountered any significant technological problems. Materials that meet the design goals exist and have been tested under nuclear reactor conditions more rigorous than those expected in the HPS. This is an important advantage for the near-term use of this space reactor. Calculations that support claims of performance and lifetime have been performed. Passive shutdown can be ensured through the wise use of specific materials. This work further demonstrates that the HPS has enormous potential as a near-term, low-cost space fission power supply.

\section{Acknowledgment}

The author wishes to thank those at Los Alamos National Laboratory who assisted me in this project and gave me extraordinary opportunities to learn.

\section{References}

Briesmeister, J. F. (1993) "MCNP - A General Monte Carlo N-Particle Transport Code," LA-12625-M, Los Alamos National Laboratory, Los Alamos, New Mexico.

Croff, A. G. (1980) “A User's Manual For ORIGEN2 Computer Code," Oak Ridge National Laboratory.

Makenas, B. J., D. M.Paxton, S. Vaidyanathan, and C. W. Hoth (1994) "SP-100 Fuel Pin Performance: Results from Irradiation Testing," in Proc. $11^{\text {th }}$ Symposium on Space Nuclear Power and Propulsion, CONF-940101, M. S. El-Genk ed., American Institute of Physics, New York, AIP Conf. Proc. No. 301.

Mason, R. E. and R. B. Matthews (1988) "Compatibility in Space Reactor Fuel Systems," LA-11071-MS, Los Alamos National Laboratory, Los Alamos, New Mexico.

Nikolaev, Y., V. Kolesov, P. Zubarev, A. Sintzov, N. Tachkova, A. Yastrebkov, and A. Gontar (1993)

"Molybdenum and Tungsten Single Crystal Alloys With Abnormally High Creep Strength For Space Nuclear Power and Propulsion Systems," in Proc. $10^{\text {th }}$ Symposium on Space Nuclear Power System, CONF-930103, M. S. El-Genk ed, American Institute of Physics, New York.

Poston, D. I. and H. R. Trellue (1997) “User’s Manual For MonteBurns,” Los Alamos National Laboratory. 